\title{
The Morphometric Examination of Head Area of Black Headed Gulls (Larus Ridibundus) from Marmara Region
}

\author{
๑ Ozan GÜNDEMİR ${ }^{1 *}$, ๑ Gülsün PAZVANT ${ }^{1}$, ๑ Nazan GEZER İNCE ${ }^{1}$
}

1 Deparment of Anatomy, Faculty of Veterinary Medicine, Istanbul University-Cerrahpasa, Istanbul, 34320, Turkey

Received 2019-10-17 Accepted 2020-02-24

\begin{abstract}
The Black-headed gull (Larus ridibundus), a gull species commonly seen on shores of Küçükçekmece lake located in Turkey’s Marmara Region. This bird does not show sexual dimorphism because as it has monomorphic feather characteristics like other gull species.. In order to perform sex discrimination in gulls, the effective discriminant function analysis (DFA) method is used for the measurements based on the external morphology and determining the variables discriminating the two sex groups. The head morphological measurements and the body weights of 28 ( 14 males and 14 females) adult Black-headed gulls were obtained. One discriminant function was determined based on the results. The accuracy rate in two sexes was determined to be $82.1 \%$ ( $85.7 \%$ female, $78.6 \%$ male) using the formula we obtained as a result of the discriminant function analysis in which the head length, determined to be more significant compared to the other variables, was used. The aim of the study is to assess the sexual dimorphism in population of Black-headed gull and represent a reliable method to make a sex discrimination along with discriminant analysis.
\end{abstract}

Key words: Avian anatomy, Black headed gulls, head morpmometry, Marmara sea.

\section{Introduction}

The Black-headed gull is a gull species commonly seen in wetlands. This bird species, that can drink salt water, is called with this name as its feathers growing on its head in winter months are black. They make their nests, mostly composed of dry sticks, on rocky areas and rooftops. This bird species, with a quite large population, are included in the least-concern species group. ${ }^{1,2}$ They are also known to steal the food of other animals. They are among the most crowded gull groups seen in Marmara Region especially during the winter months. They may migrate due to bad weather conditions. ${ }^{2,3}$

It is estimated that 7.3-11 million Black-headed gulls live in an area of 10 million $\mathrm{km} 2$ in the world. There are vari- ous studies on this species that has a quite large population in Europe. It has been tried to calculate the number of the nests made by this bird species especially around Czech Republic and Poland and to determine their change within a year. ${ }^{4,5}$ The nesting colonies around Netherlands and Belgium have been counted and the information on their inland and coastal colonies has been obtained. ${ }^{6}$

Turkey has an importance in terms of bird migratory routes due to its flora and fauna brought by its biogeographical properties. ${ }^{7}$ It has been reported that 485 bird species have been determined in the recent counts performed within this context. Küçükçekmece Lake, located in the European side of Istanbul, is one of the centres where this count has been made. ${ }^{8}$ In the count of winter water birds performed in 2018, it was reported that 22 species have been

* Corresponding author: Ozan GÜNDEMİR, e-mail: ozan_gundemir@hotmail.com, tel: +90 5396610444

Istanbul University-Cerrahpasa, Faculty of Veterinary Medicine, Deparment of Anatomy, 34320, Avc1lar/Istanbul, Turkey 
observed in this region and totally 22.022 birds were inhabiting in this region. ${ }^{9}$ It was also reported in this count that black-headed gulls were among the 15 most abundant bird species.

As the gull species have monomorphic feather traits, ${ }^{10}$ they do not exhibit sexual dimorphism. However, there are dimensional differences between males and females. ${ }^{11-13}$ There are numerous studies in which an effective statistical assessment (discriminant function analysis-DFA) has been made in the measurements based on the external morphology and determining the variables discriminating the two sex groups, in order to perform sex discrimination in gulls. Also, it is known that the various dimensional measurements obtained external morphology vary in many species $^{14-16}$ and a separate discriminating function analysis is needed for each subspecies. ${ }^{12,13,17}$

The aim of the study; To assess the sexual dimorphism in Black Headed gull population in Küçükçekmece Lake and its surrounding located in Marmara Region and to present a reliable method to make the sex discrimination of black-headed gulls in the population, along with discriminant analysis.

\section{Materials and Methods}

In the present study, a total of 28 dead adult Black-headed gulls including 14 males and 14 females which were brought to Istanbul University-Cerrahpaşa, Faculty of Veterinary Science, were used. The present study was approved by Istanbul University-Cerrahpasa, Faculty of Veterinary Medicine, Local Ethics Committee (Decision no: 13/02/2019-25832). It was known that these gulls were brought from Küçükçekmece Lake and its surrounding. This is a lake with low salinity located in $15 \mathrm{~km}$ west of Istanbul and at sea level. It is connected with sea and it is located on the important migratory routes for bird species (Fig. 1).

The weights of the gulls were measured using a $0.01 \mathrm{mg}$ precision digital scale. The morphometric measurements were calculated in millimetres $(\mathrm{mm})$ using a digital calliper. The head morphometric measurements of the Black-headed gulls were obtained from the specified points in the literature (Fig. 2);11,12,18,19,20

1-Nalopsi

2-Bill Length-1

3-Bill Length-2

4-Bill Length-3

5-Head Length

6-Bill Depth-1 (Gony)
7-Bill Depth-2

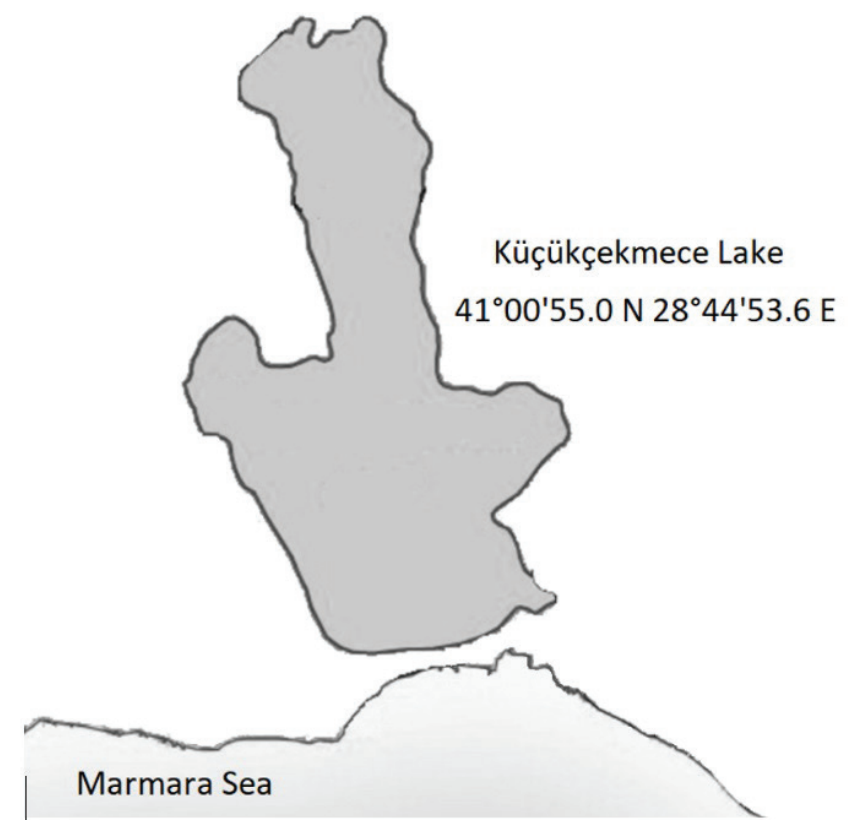

Figure 1. Location of Kucukcekmece Lake.
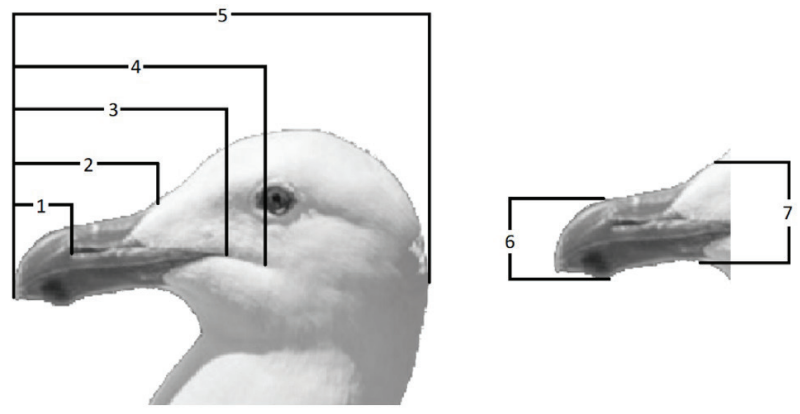

Figure 2. The morphometric measurements of the head of the Black-headed gull. 1: Nalopsi, 2: Bill length-1, 3: Bill length-2, 4: Bill length-3, 5: Head length, 6: Bill depth-1 (gony), 7: Bill depth-2.

After male and female individuals were determined by using the abdominal dissection method, they were grouped. The values of each group of Black-headed gulls were obtained separately and recorded into the computer. The results were assessed in the electronical environment.

The data used in the present study were assessed using Statistical Package for the Social Science (SPSS) for Windows 21 packaged software. The inter-sex groups were compared by applying "independent samples t-test" and the significant ones were specified.

The discriminant function analysis was performed in order to estimate sexes. The morphometric measurements, which were significant in the study, were used in the analysis. The significant variables were multiplied with their own 
raw coefficients and a discriminant formula was formed. The explanatoriness was obtained by squaring canonical correlation. Those with high correlation coefficient $(>0.7)$ among all the variables were determined.

\section{Results}

As a result of the analysis made on the morphometric measurements obtained from the heads of 28 Black-headed gulls which were collected from Küçükçekmece Lake and its surrounding and whose weights were measured, it was observed that the differences between the males and females in terms of nalopsi, head length and bill depth-1 were significant $(\mathrm{P}>0.05)$. It was determined that the difference between the other morphometric characteristics, including weight, was not significant. Table 1 shows the mean values, standard deviations, and coefficient of variance of the measurement values of the gulls.

Table 1. Body measurement of male and female Blackhead Gulls from the Kucukcekmece Lake colony, Istanbul.

\begin{tabular}{|c|c|c|c|c|c|c|}
\hline & Sexes & $\mathbf{n}$ & Mean (mm) & SD & $\mathbf{t}$ & CV (\%) \\
\hline \multirow[t]{2}{*}{ Nalopsi } & to & 14 & 16,16 & 1,12 & \multirow{2}{*}{$0,036^{*}$} & 6,91 \\
\hline & 8 & 14 & 17,06 & 1,05 & & 6,14 \\
\hline \multirow[t]{2}{*}{ Bill Length-1 } & to & 14 & 50,37 & 2,82 & 0,242 & 5,59 \\
\hline & $\delta$ & 14 & 51,78 & 3,41 & & 6,59 \\
\hline \multirow[t]{2}{*}{ Bill Length-2 } & to & 14 & 39,52 & 2,06 & 0,332 & 5,20 \\
\hline & $\delta$ & 14 & 40,50 & 3,10 & & 7,65 \\
\hline \multirow[t]{2}{*}{ Bill Length-3 } & to & 14 & 33,20 & 1,89 & 0,101 & 5,69 \\
\hline & 8 & 14 & 34,62 & 2,48 & & 7,15 \\
\hline \multirow[t]{2}{*}{ Head Length } & to & 14 & 80,01 & 2,94 & $0,01^{*}$ & 3,68 \\
\hline & o & 14 & 84,23 & 2,80 & & 3,33 \\
\hline \multirow[t]{2}{*}{ Bill Depth-1 } & to & 14 & 7,82 & 0,43 & $0,024^{*}$ & 5,54 \\
\hline & $\delta$ & 14 & 8,26 & 0,54 & & 6,51 \\
\hline \multirow[t]{2}{*}{ Bill Depth-2 } & to & 14 & 9,65 & 0,71 & 0,139 & 7,33 \\
\hline & $\delta$ & 14 & 10,07 & 0,76 & & 7,52 \\
\hline \multirow[t]{2}{*}{ Weight } & to & 14 & 195,00 & 32,96 & 0,079 & 16,90 \\
\hline & $\delta$ & 14 & 221,07 & 41,87 & & 18,94 \\
\hline
\end{tabular}

A high correlation was observed between head length and bill length-1 (0.76), between head length and bill length-3 (0.86), between head length and Nalopsi (0.78) and between bill length-1 and bill length-3 (0.71). It was determined that the covariance matrices were equal. The discriminant analysis was applied between the values that were significant in sex-estimation. Wilks Lambda and F values of the morphometric measurements were examined by discriminant analysis method. It was observed that the head length, nalopsi and bill depth-1 (Gony) were statistically significant (Table 2). One discriminant function was determined using the results. It was observed that the head length was more significant compared to the other variables. The discriminant analysis provided the correct determination of $78.6 \%$ of the males and $85.7 \%$ of the females. It was observed that $82.1 \%$ of the analyses performed using the head length only was correct for both sexes.

Table 2. Wilks Lambda value and F value of the morphometric measurement data.

\begin{tabular}{|l|l|l|l|}
\hline Morphometric measurements & Wilks' Lambda & F & Sig. \\
\hline Head lenght &, 633 & 15,078 &, 001 \\
\hline Nalopsi &, 842 & 4,870 &, 036 \\
\hline Bill Depth-1 &, 818 & 5,774 &, 024 \\
\hline
\end{tabular}

\section{The function equation for sex-determination:}

In the validation of the discriminant function analysis performed with the females, it was observed that when the formula was applied for 14 females, the values of 12 individuals were under below zero and 11 of 14 individuals in the males had a result value above zero. It was determined that the analysis mean values were -0.734 in the females and 0.734 in the males.

\section{Discussion and Conclusion}

Sex-determination in birds is an important prerequisite for the ecological and behavioural studies and the population of a region. However, sex-determination in the species with monomorphic feather character is a quite difficult, time-consuming and expensive procedure. But it is known that the morphological measurements in many poultry species are higher in males compared to females.

It was observed as a result of the analyses performed in the present study that only the head length was one of the distinctive features in sex-determination. It has been reported in the studies conducted with the gulls in the Baltic Sea, 19 Ivory gulls ${ }^{21}$ and Western Europe population Black-headed gulls $\mathrm{s}^{22}$ that the bill depth is also a distinctive functional measurement as well as the head length. However, it has been stated that the gony depth continues to increase with increasing age after sexual maturity and therefore, this value may cause a mistake in DFA. ${ }^{23}$ The effect of the other morphological characteristics on the discriminant function, in sex-determination, has been quite low in the other studies, as in the present study.

In another study, it was reported that the accuracy rate in the two sexes in 21 adult water birds using the wing and bill depths was $95 \%$ (100\% females, $92 \%$ males). ${ }^{24}$ However, as 
the wing length increases with increasing age, it is obvious that using it for the birds, the age of which are not known, will not give correct results. In the present study, we used the morphometric characteristics of the heads of 28 adult Black-headed gulls. From these morphometric results, it was determined that the accuracy rate in two sexes was $82.1 \%$ ( $85.7 \%$ female, $78.6 \%$ male) using the formula we obtained as a result of the discriminant function analysis in which the head length was used.

The gulls used in the present study were included in adult age group. It was reported in the studies that the body weights become significant after 10 days and the body size became significant in the chick gulls between the two sexes after 15 days. ${ }^{25}$ Also, in order to ensure that the use of body weight in DFA is effective in poultry, it should be measured in the same stage of the season and there is no variation among years. ${ }^{26}$ In the present study, the highest CV value was observed in body weight. However, the fact that the body weight did not exhibit sexual dimorphism in Black-headed gulls was considered to be due to the use of the adult gulls in different seasons.

In a study conducted with the species of black-backed gulls, it was stated that the head length, bill depth and tarsal length were used as a distinctive feature. In this study, generalized linear modelling procedure was used as well as discriminant analysis. ${ }^{27}$ In the mentioned study, the result demonstrating that all the morphometric measurements of the male gulls are higher compared to the female gulls is parallel with the present study. As the aim of the present study was only to reveal the distinctive features between male and female Black-headed gulls, it was considered that discriminant analysis method would be enough. It was also observed that this distinction could be performed with the head morphometric measurements together with the significant data obtained in the results.

There are many morphometric and morphological methods for sex-determination in veterinary anatomy studies. But, the morphometric measurements, which are the most effective in sex-determination, are used in the DFA applied in various gull populations and this is one of the best techniques used in the field studies. However, its usefulness should be tested in the other populations. Because applying a DFA analysis function obtained in a population to different populations may be risky as the possible morphological differences between the gulls with different origins. In the present study, it was aimed to obtain the reference information for sex-determination by examining the Black-headed gull species in Küçükçekmece Lake and its surrounding. We think that we can perform sex-determination in accordance with the function obtained by using these outputs. These functions may provide a quick, easy, cheap and non-invasive way to identify male and female gulls in the ecological studies conducted on the sex-specific differences. This study, which also represents the morphometric characteristics of Black-headed gull species, provides reference values that can be used effectively in sex-determination using the external morphological structure in the further studies to be conducted in terms of taxonomy and in the field studies of ornithologists.

\section{References}

1. Birdlife international 2016 species factsheet. Larus ridibundus. http://datazone.birdlife.org/species/factsheet/Mew-Gull. Accessed March 28, 2019.

2. Karabaş martı. http://www.trakus.org. Accessed March 28, 2019.

3. Karabaş martı. https://evrimagaci.org/karabas-marti-chroicocephalus-ridibundus-5264. Accessed March 28, 2019.

4. Musil P, Musilová Z, Fuchs R, et al. Long-term changes in numbers and distribution of wintering waterbirds in the Czech Republic, 1966-2008. Bird Study. 2011;58(4):450-460.

5. Poprach K, Machar I, Maton K. Long-term decline in breeding abundance of Black-headed Gull (Chroicocephalus ridibundus) in the Czech Republic: a case study of a population trend at the Chomoutov lake. Ekológia (Bratislava). 2016;35(4):350-358.

6. Van Dijk JG, Stienen EW, Gerritsen S, et al. Reproductie van de Kokmeeuw in kust-en binnenlandkolonies. Limosa. 2009;82(1):13.

7. Yilmaz KT. Ecological diversity of the Eastern Mediterranean region of Turkey and its conservation. Biodivers Conserv. 1997;7(1):87-96.

8. Kılıç DT, Eken G. Türkiye’nin önemli kuş alanları 2004 güncellemesi. Doğa Derneği Ankara. 2004;74-100.

9. Kış ortası su kuşu sayımı 2018. Doğa koruma ve milli parklar genel müdürlüğü (İKGT 2010). http://www. milliparklar.gov.tr/dosyalar/kosks_raporu2018.pdf. Accessed March 28, 2019.

10. Del Hoyo J, Elliott A, Sargatal J. Handbook of the birds of the world. 1thed. Barcelona: Lynx Edicions; 1996.

11. Galarza A, Hidalgo J, Ocio G, et al. Sexual size dimorphism and determination of sex in Atlantic yellow-legged gulls Larus michahellis lusitanius from northern Spain. Ardeola. 2008;55(1):41-47.

12. Evans DR, Hoopes EM, Griffin CR. Discriminating the sex of laughing gulls by linear measurements (Identi- 
ficación del sexo en individuos de Larus atricilla utilizando medidas lineares). J Field Ornithol. 1993;472476.

13. Evans DR, Cavanagh PM, French TW, et al. Identifying the sex of Massachusetts Herring Gulls by linear measurements. J Field Ornithol. 1995;66(1):128-132.

14. Renner M, Davis LS. Sexing little penguins Eudyptula minor from Cook Strait, New Zealand using discriminant function analysis. Emu. 1999;99(1):74-79.

15. Palomares, LE, Arroyo BE, Marchamalo J, et al. Sexand age-related biometric variation of Black-headed Gulls Larus ridibundus in western European populations. Bird Study. 1997;44(3):310- 317.

16. Aguirre JI, Arana P, Antonio MT. Testing effectiveness of discriminant functions to sex different populations of Mediterranean Yellow-Legged Gulls Larus michahellis michahellis. Ardeola. 2009;56(2): 281-286.

17. Hammouda A, Selmi S. Morphometric sexing of Mediterranean Yellow-legged Gulls Larus michahellis michahellis breeding in the Gulf of Gabès, southern Tunisia. Ostrich. 2013;84(2):119-122.

18. Bosch M. Sexual size dimorphism and determination of sex in Yellow-Legged Gulls (Dimorfismo sexual de tamaño y determinación del sexo en gaviotas patiamarillas). J Field Ornithol. 1996;67(4):534-541.

19. Meissner W, Kośmicki A, Niemczyk A, et al. Development of sexual dimorphism and sexing of Baltic Herring Gull (Larus argentatus argentatus) in successive age classes. Waterbirds. 2017;40(1):24-33.

20. İnce NG, Demircioğlu İ, Yilmaz B, et al. Martılarda (Laridae spp.) cranium'un üç boyutlu modellemesi. Harran Üniv Vet Fak Derg. 2018;7(1): 98-101.

21. Yannic G, Broquet T, Strøm H, et al. Genetic and morphological sex identification methods reveal a male-biased sex ratio in the Ivory Gull Pagophila eburnea. J Ornithol. 2016;157(3):861-873.

22. Palomares LE, Arroyo B, Marchamalo J, et al. Sex- and age-related biometric variation of black-headed Gulls Larus ridibundus in Western European populations. Bird Study. 1997;44(3):310-317.

23. Coolson JC, Duncan N, Thomas CS, et al. An age-related difference in the bill depth of Herring Gulls Larus argentatus. Ibis. 1981;123(4):499-502.

24. Stermin AN, David A, Eilers A, et al. A better sex discriminator? Validity of sex-discriminating formulas in water rails Rallus aquaticus L., 1758 (Rallidae). North-Western Journal of Zoology. 2018;14(2):208212.

25. Jordi O, Arizaga J. Sex differences in growth rates of Yellow-legged Gull Larus michahellis chicks. Bird study. 2016;63(2):273-278.
26. Taylor S, Jamieson IG: Determining sex of South Island saddlebacks (Philesturnus carunculatus carunculatus) using discriminant function analysis, Notornis. 2007;54(2):61-64.

27. Hallgrimsson GT, Helgason HH, Palsdottir ES, et al. Sexing adult and fledgling Lesser Black-backed Gulls from morphometrics. Ringing Migr. 2016;31(1):68-73. 